\title{
An Evaluation of Acute Toxicity of Colloidal Silver Nanoparticles
}

\author{
Pattwat MANEEWATTANAPINYO1), Wijit BANLUNARA ${ }^{2)}$, Chuchaat THAMMACHAROEN ${ }^{1)}$, \\ Sanong EKGASIT ${ }^{1)}$ and Theerayuth KAEWAMATAWONG ${ }^{2) *}$ \\ ${ }^{1)}$ Sensor Research Unit, Department of Chemistry, Faculty of Science and ${ }^{2)}$ Department of Veterinary Pathology, Faculty of Veterinary \\ Science, Chulalongkorn University, Bangkok 10330, Thailand
}

(Received 29 January 2011/Accepted 15 June 2011/Published online in J-STAGE 29 June 2011)

ABSTRACT. Tests for acute oral toxicity, eye irritation, corrosion and dermal toxicity of colloidal silver nanoparticles (AgNPs) were conducted in laboratory animals following OECD guidelines. Oral administration of AgNPs at a limited dose of 5,000 mg/kg produced neither mortality nor acute toxic signs throughout the observation period. Percentage of body weight gain of the mice showed no significant difference between control and treatment groups. In the hematological analysis, there was no significant difference between mice treated with AgNPs and controls. Blood chemistry analysis also showed no differences in any of the parameter examined. There was neither any gross lesion nor histopathological change observed in various organs. The results indicated that the $\mathrm{LD}_{50}$ of colloidal AgNPs is greater than $5,000 \mathrm{mg} / \mathrm{kg}$ body weight. In acute eye irritation and corrosion study, no mortality and toxic signs were observed when various doses of colloidal AgNPs were instilled in guinea pig eyes during $72 \mathrm{hr}$ observation period. However, the instillation of AgNPs at 5,000 ppm produced transient eye irritation during early $24 \mathrm{hr}$ observation time. No any gross abnormality was noted in the skins of the guinea pigs exposed to various doses of colloidal AgNPs. In addition, no significant AgNPs exposure relating to dermal tissue changes was observed microscopically. In summary, these findings of all toxicity tests in this study suggest that colloidal AgNPs could be relatively safe when administered to oral, eye and skin of the animal models for short periods of time.

KEY WORDS: acute toxicity, colloidal silver nanoparticles, dermal, eye, oral.

J. Vet. Med. Sci. 73(11): 1417-1423, 2011

Engineered nanoparticles (NP) are defined as materials produced within the nanoscale range of $1-100 \mathrm{~nm}$ in length or diameter that exhibit unique novel properties of the structural integrity as well as physical and chemical properties [26]. Over the past few decades, nanomaterials have had a great impact and gained enormous attention in science, technology and business because of their potential for achieving specific processes and selectivity. Although the applications and benefits of these engineered nanomaterials are extensively and currently being widely used in modern technology and many commercial and medical sectors, there is still limited information concerning human health and environmental impacts. Several studies expected that nanoparticles could lead to unexpected health or environmental hazards because of their unique properties such as extremely high surface area and increased reactivity [7].

Silver nanoparticles (AgNPs), one of the most commonly used metal-nanoparticles, have been known to have a wide range of applications including solar energy absorption coatings, chemical catalysts and especially antimicrobial agents. AgNPs have potentials for inhibitory and bactericidal effects as well as retarding the growth of mold, harmful spores and germs [5]. Compared to bulk silver metal, AgNPs are expected to have higher antimicrobial activity due to their high specific surface area and high fraction of surface atoms. Because of these properties, AgNPs are

\footnotetext{
* Correspondence to: Assistant Prof. Dr. Kaewamatawong, T., Department of Veterinary Pathology, Faculty of Veterinary Science, Chulalongkorn University, Henri Dunant Rd, Patumwan, Bangkok 10330, Thailand.

e-mail: theerayuth71@hotmail.com
}

added to numerous consumer products including textiles, home appliances, paints, food supplements and even health applications. Despite the varied uses of these AgNPs in many commercial products that launched into the market recently, there is a lack of information on the basic toxicity of silver nanoparticles regarding the health implications, occupational risks and hazards. Thus, the objective of this study was to investigate the acute toxicity of AgNPs by in vivo experiments. Tests for acute oral toxicity, eye irritation, corrosion and dermal toxicity were conducted using the recommended Organization for Economic Cooperation and Development (OECD) guidelines for the testing of chemicals for safety evaluation. Furthermore, lethal Dose $50\left(\mathrm{LD}_{50}\right)$ in acute oral toxicity test was evaluated.

\section{MATERIALS AND METHODS}

Preparation and characterization of AgNPs: High concentration of colloidal AgNPs solution was synthesized via chemical reduction process according to the method previously described with same minor modifications [14, 23]. Briefly, a $0.094 \mathrm{M}$ aqueous solution of silver nitrate $\left(\mathrm{AgNO}_{3}\right.$; Merck) was prepared with soluble starch (Merck) as a stabilizer. An aqueous solution of $0.07 \mathrm{M}$ sodium borohydride $\left(\mathrm{NaBH}_{4}\right.$; Merck) reducing agent with the soluble starch solution as a solvent were equentially prepared. By mixing both solutions, the $\mathrm{AgNO}_{3}$ solution was added dropwise to the $\mathrm{NaBH}_{4}$ solution under a vigorous stirring. A dark cloud appeared and turned to yellowish brown within a few seconds. When all reactants were completely added, the solution turned dark brown. The purification of the 


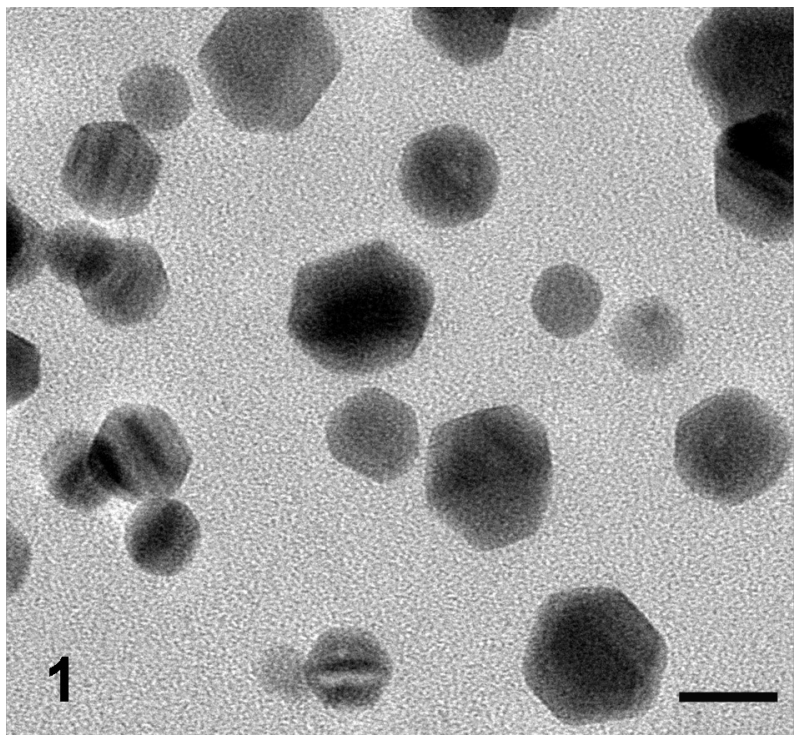

Fig. 1. Transmission electron microscopy of Colloidal AgNPs demonstrated spherical or polygonal shape of particles with diameter size of $10-20 \mathrm{~nm}(\mathrm{bar}=16 \mathrm{~nm})$.

AgNPs was precipitated using the centrifugation. Then, the purified AgNPs were washed three times with DI water and adjusted to the same volume before dilution. The percentage purity of the AgNPs was measured from free $\mathrm{Ag}$ ion concentration in the original AgNPs solution (10,000 ppm) using the macro- and microelectrode [15]. The results showed that the Ag ion concentration was contented at 3.77 \pm 0.2 and $3.61 \pm 0.2 \mathrm{ppm}$ with the macro- and microelectrode, respectively. Therefore, AgNPs in this study was very pure (99.96\%) and Ag ions were very low concentrated (less than 0.04\%). The AgNPs solutions were diluted with distilled water to obtain various concentrations of AgNPs prior to use. The particle morphology of AgNPs was observed using JEOL JEM-2010 analytical transmission electron microscope (Fig. 1). The AgNPs had a spherical configuration which had a primary particle diameter of 10 $20 \mathrm{~nm}$. The plasmon extinction of AgNPs was measured by Ocean Optics Portable UV-Visible spectrometer (USB 4000-UV-VIS detector) shown in Fig. 2. The maximum of extinction spectrum ( $\lambda \max$ ) of AgNPs was at $395 \mathrm{~nm}$ with a narrow full width at half height $(\mathrm{FWHH})$ about $45 \mathrm{~nm}$. This result indicated that the size distribution of AgNPs was narrow.

Animal treatments: All laboratory animals were purchased from National Laboratory Animal Centre, Mahidol University. Eighteen male and 18 female ICR mice (10-12 weeks old, 28-35 g body weight) were used in acute oral toxicity test. Eight and nine male guinea pigs weighing 500-650 g were used for acute eye irritation and corrosion test and acute dermal toxicity test, respectively. The animals were housed in an animal facility under 12:12 hr lightdark cycle, temperature of $24 \pm 1^{\circ} \mathrm{C}$, relative humidity of 55 $\pm 10 \%$ and negative atmospheric pressure. They were pro-

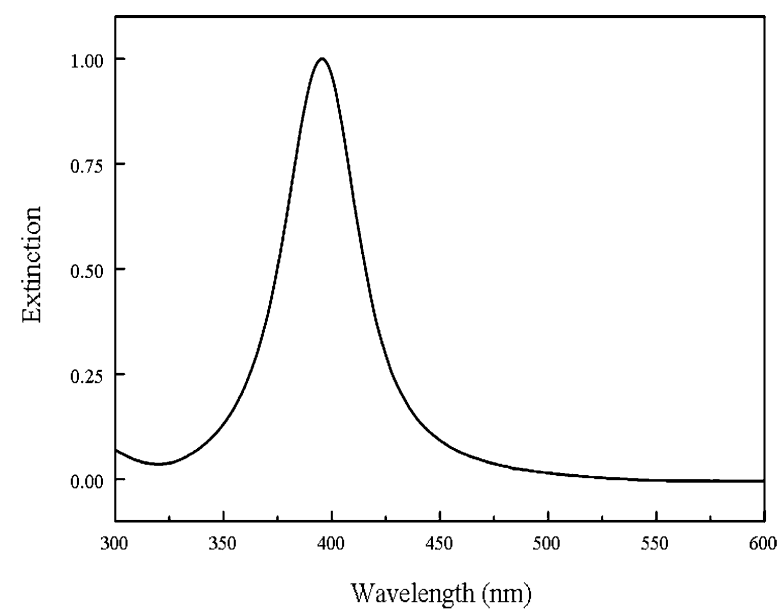

Fig. 2. The plasmon extinction spectrum of diluted 100-1,000 from high concentration of colloidal AgNPs (10,000 ppm) showed $\lambda_{\max }$ at $395 \mathrm{~nm}$.

vided with pelleted food and filtered tap water ad libitum throughout the experiment. All animal experiments were performed according to OECD guidelines and were proved by the ethics committee of Chulalongkorn University Animal Care and Use Committee (CU-ACUC).

The acute oral toxicity test of colloidal AgNPs was evaluated in mice using the up and down procedure [18]. Mice of either sex received colloidal AgNPs at the limited dose of $5,000 \mathrm{mg} / \mathrm{kg}$ orally using a suitable intubation cannula. The animals were observed for toxic symptoms continuously for the first $3 \mathrm{hr}$ after dosing. Finally, the number of survivors was noted after $24 \mathrm{hr}$ and these animals were then maintained for 14 days further with observations made daily. At 1, 7 and 14 days after gavage, six mice in each group were sacrificed. Whole blood was collected for routine clinical pathology and blood chemical parameters including serum glutamic oxaloacetic transaminase (SGOT), serum glutamic pyruvic transaminase (SGPT), serum creatinine, triglyceride, cholesterol and total protein. Various organs such as lung, hilar lymph node, heart, liver and kidney were collected in $10 \%$ buffered neutral formalin for routine histopathological evaluations.

For acute eye irritation and corrosion test, the guinea pigs were randomly divided into 2 groups containing 4 animals each in the following manner: group 1,50 ppm of colloidal AgNPs and group 2, 5,000 ppm of colloidal AgNPs. The procedure used for determining the ocular toxicity of the above chemicals followed the procedures as recommended and documented by OECD 405; acute eye irritation and corrosion [17]. Briefly, the $0.1 \mathrm{~m} l$ of colloidal AgNPs suspension was placed in the conjunctival sac of one eye of each animal after gently pulling the lower lid away from the eyeball. Another eye, which remains untreated, served as a control by being instilled with $0.1 \mathrm{~m} l$ of distilled water. All animals were observed for toxic symptoms continuously at $1,12,24,48$ and $72 \mathrm{hr}$ after dosing. The eye reactions of 
iris, conjunctivae, cornea and chemosis were graded following the grading system of OECD 405 guideline. The animals were then maintained and observed for toxic signs for further 14 days with observations made daily.

For acute dermal toxicity test, the guinea pigs were randomly divided into 3 groups containing 3 animals each in the following manner: group 1, distilled water (vehicle control); group 2 and group 3, 50 and 100,000 ppm of colloidal AgNPs, respectively. All treated groups received the above chemicals at $2 \mathrm{~m} l$. The procedure used for determining the dermal toxicity of the above chemicals followed the procedures as recommended and documented by OECD 434; acute dermal toxicity-fixed dose procedure [19]. Briefly, colloidal AgNPs suspension was applied to a shaved area of skin, an approximately $7 \times 10 \mathrm{~cm}$ rectangle. The chemical was left in contact with the skin covered by porous gauze dressing and non-irritating tape for $24 \mathrm{hr}$. All animals were observed for toxic symptoms continuously at 1, 3, 7 and 14 $\mathrm{hr}$ after dosing. After $24 \mathrm{hr}$ exposure period, every residue was removed by washing the area with distilled water. The number of survivors was noted after $24 \mathrm{hr}$ and these animals were then maintained and observed for toxic signs for 14 days further with observations made daily. At 1, 3, and 7 days after exposure, skin biopsy was performed for routine histopathological evaluations. All animals were sacrificed after a 14 day observation period and their skins were collected for histopathological examination.

Table 1. Percentage of body weight gain of mice after treatment with colloidal AgNPs

\begin{tabular}{crrr}
\hline \multirow{2}{*}{ Treatment } & \multicolumn{3}{c}{ \% body weight gain } \\
\cline { 2 - 4 } & \multicolumn{1}{c}{ Day 1 } & Day 7 & Day 14 \\
\hline Control & & & \\
Male & $1.17 \pm 0.55$ & $7.15 \pm 0.64$ & $3.98 \pm 0.83$ \\
Female & $-0.24 \pm 0.34$ & $0.5 \pm 0.37$ & $2.41 \pm 2.28$ \\
AgNPS & & & \\
Male & $-3.87 \pm 1.09$ & $1.58 \pm 4.94$ & $5.45 \pm 0.6$ \\
Female & $0.69 \pm 0.43$ & $0.65 \pm 0.42$ & $3.69 \pm 1.73$
\end{tabular}

* All data are expressed as means \pm SD and were compared with the ANOVA $(\mathrm{n}=3)$

Differences with $P<0.05$ are considered statistically significant.
Statistical analysis: All results from Table 1, 3 and 4 were presented as mean \pm standard deviation (SD). Data were analyzed using analysis of variance (ANOVA; Tukey' multiple comparison method). Values of $P<0.05$ were considered as the level statistical significance. Statistical analysis was performed using the SPSS statistical software for Windows, version 12. The ocular lesions in Table 2 were graded following the guidelines at each time point.

\section{RESULTS}

Clinical and general signs: In all acute toxicity tests, no death was recorded in the 14 days of observation period in all control and treated animals. The animals did not show any significant changes in the general appearance during the observation period. There were no significant differences in the percentage of weight gain between the control and treatment groups of both male and female mice given $5,000 \mathrm{mg} /$ $\mathrm{kg}$ of the colloidal AgNPs orally (Table 1). Percentage of body weight gain AgNPs in male mice on the first day decreased. Moreover, some mice from this group showed bite wounds in scrotal areas and tails. No significant changes in water / food consumption, \% weight gain and behavior of guinea pigs in acute eye and dermal toxicity test were also observed during the observation time (data not shown).

Hematology and clinical chemistry: The hematological analysis in acute oral toxicity test showed no significant changes of $\mathrm{RBC}, \mathrm{Hb}, \mathrm{Ht}, \mathrm{MCV}, \mathrm{MCH}, \mathrm{MCHC}$, platelets and $\mathrm{WBC}$ in the male and female treatment groups compared to the control groups. The leukocyte differential count showed no significant difference between the control and treated groups (Table 3). There were no significant differences in any of the biochemical parameters examined in either the control or treated group of the male and female mice (Table 4).

Gross and histopathology: There was no significant lesion on gross findings in any observation time of all acute toxicity tests. In acute eye irritation and corrosion test, some animals from 5,000 ppm AgNPs treated group showed grade 1 of conjunctivae irritation, which some blood vessels hyperemia in conjunctivae were observed during the first 24

Table 2. Grading of ocular lesions of guinea pigs after treatment with colloidal AgNPs

\begin{tabular}{cccccc}
\hline \multirow{2}{*}{ Treatment } & \multirow{2}{*}{$\begin{array}{c}\text { Observation time } \\
(\mathrm{hr})\end{array}$} & \multicolumn{4}{c}{ Grading of ocular lesions } \\
\cline { 3 - 6 } $50 \mathrm{ppm}$ & 1 & 0 & 0 & 0 & 0 \\
& 12 & 0 & 0 & 0 & 0 \\
& 24 & 0 & 0 & 0 & 0 \\
& 48 & 0 & 0 & 0 & 0 \\
$5,000 \mathrm{ppm}$ & 72 & 0 & 0 & 0 & 0 \\
& 1 & 0 & 0 & 1 & 0 \\
& 12 & 0 & 0 & 1 & 0 \\
& 24 & 0 & 0 & 1 & 0 \\
& 48 & 0 & 0 & 0 & 0 \\
\hline
\end{tabular}

* Data are graded following the grading system of OECD 405 guideline., $\mathrm{n}=4$. 
Table 3. Hematological values of mice after treatment with colloidal AgNPs

\begin{tabular}{|c|c|c|c|c|c|c|c|c|c|c|c|c|}
\hline \multirow{2}{*}{\multicolumn{2}{|c|}{ Day Group }} & \multicolumn{11}{|c|}{ Hematological parameter $\left.{ }^{a}\right)$} \\
\hline & & $\begin{array}{c}\mathrm{RBC} \\
\left(\times 10^{6}\right)\end{array}$ & $\begin{array}{c}\mathrm{Hb} \\
(\mathrm{g} / \mathrm{d} l)\end{array}$ & $\begin{array}{l}\mathrm{Ht} \\
(\%)\end{array}$ & $\begin{array}{l}\mathrm{MCV} \\
\left(\mu \mathrm{m}^{-3}\right)\end{array}$ & $\begin{array}{l}\mathrm{MCH} \\
(\mathrm{pg})\end{array}$ & $\begin{array}{c}\mathrm{MCHC} \\
(\mathrm{g} / \mathrm{d} l)\end{array}$ & $\begin{array}{c}\text { PLT } \\
\left(\times 10^{3} \mathrm{~mm}^{-3}\right)\end{array}$ & $\begin{array}{l}\text { WBC } \\
\left(\times 10^{3}\right)\end{array}$ & $\begin{array}{l}\text { Lymp } \\
\left(\times 10^{3}\right)\end{array}$ & $\begin{array}{l}\text { Mono } \\
\left(\times 10^{3}\right)\end{array}$ & $\begin{array}{c}\text { Granular } \\
\left(\times 10^{3}\right)\end{array}$ \\
\hline \multicolumn{13}{|c|}{1 Control } \\
\hline & Male & $6.2 \pm 0.33$ & $11.43 \pm 0.46$ & $35.15 \pm 1.42$ & $56.9 \pm 2.44$ & $18.43 \pm 0.79$ & $32.28 \pm 0.22$ & $518.5 \pm 73.9$ & $2.5 \pm 1.3$ & $0.39 \pm 0.16$ & $0.74 \pm 0.6$ & $1.74 \pm 0.94$ \\
\hline & Female & $5.9 \pm 0.44$ & $10.7 \pm 0.95$ & $33.13 \pm 2.3$ & $56.8 \pm 0.25$ & $18.3 \pm 0.41$ & $32.23 \pm 0.81$ & $455.5 \pm 59.9$ & $3.2 \pm 1.6$ & $0.49 \pm 0.22$ & $0.51 \pm 0.26$ & $2.15 \pm 1.13$ \\
\hline \multicolumn{13}{|c|}{$A g N P S$} \\
\hline & Male & $6.5 \pm 0.65$ & $12.03 \pm 1.2$ & $36.9 \pm 3.48$ & $57 \pm 1.04$ & $18.6 \pm 0.48$ & $32.6 \pm 0.34$ & $599.3 \pm 134.1$ & $2.5 \pm 0.8$ & $0.29 \pm 0.05$ & $0.31 \pm 0.04$ & $1.9 \pm 0.79$ \\
\hline & Female & $6.04 \pm 0.5$ & $11.03 \pm 0.83$ & $34.83 \pm 2.74$ & $57.6 \pm 1.15$ & $18.3 \pm 0.39$ & $31.73 \pm 0.31$ & $397.75 \pm 50.9$ & $2.07 \pm 0.7$ & $0.34 \pm 0.12$ & $0.32 \pm 0.12$ & $1.42 \pm 0.5$ \\
\hline \multicolumn{13}{|c|}{7 Control } \\
\hline & Male & $6.2 \pm 0.5$ & $10.85 \pm 0.76$ & $33.5 \pm 3.91$ & $53.9 \pm 2.97$ & $17.48 \pm 0.51$ & $32.55 \pm 2.54$ & $476 \pm 147.9$ & $2.5 \pm 0.78$ & $0.4 \pm 0.11$ & $0.45 \pm 0.11$ & $1.7 \pm 0.58$ \\
\hline & Female & $5.56 \pm 0.6$ & $10.2 \pm 1.07$ & $31.8 \pm 3.58$ & $57.2 \pm 2.07$ & $18.38 \pm 0.22$ & $32.25 \pm 1.2$ & $409.25 \pm 92.6$ & $2.1 \pm 0.67$ & $0.32 \pm 0.017$ & $0.33 \pm 0.16$ & $1.4 \pm 0.39$ \\
\hline \multicolumn{13}{|c|}{$A g N P S$} \\
\hline & Male & $5.74 \pm 0.9$ & $10.1 \pm 1.71$ & $31.9 \pm 4.83$ & $55.8 \pm 2.97$ & $17.58 \pm 0.43$ & $31.5 \pm 2.27$ & $568.3 \pm 134.5$ & $2.8 \pm 0.97$ & $0.22 \pm 0.16$ & $0.24 \pm 0.11$ & $2.15 \pm 1.1$ \\
\hline & Female & $6.26 \pm 1.5$ & $11.35 \pm 2.44$ & $34.98 \pm 8.1$ & $42.8 \pm 24.8$ & $18.18 \pm 0.59$ & $32.5 \pm 0.93$ & $514.5 \pm 125.1$ & $2.1 \pm 0.82$ & $0.31 \pm 0.11$ & $0.31 \pm 0.11$ & $1.44 \pm 0.64$ \\
\hline \multicolumn{13}{|c|}{14 Control } \\
\hline & Male & $5.79 \pm 0.5$ & $10 \pm 0.72$ & $31.7 \pm 2.16$ & $54.8 \pm 1.59$ & $17.28 \pm 0.36$ & $31.5 \pm 0.36$ & $417.3 \pm 116.6$ & $2.8 \pm 0.83$ & $0.51 \pm 0.16$ & $0.52 \pm 0.16$ & $1.8 \pm 0.51$ \\
\hline & Female & $6.55 \pm 1.3$ & $11.65 \pm 2.04$ & $36.7 \pm 6.61$ & $56.1 \pm 3.54$ & $17.85 \pm 0.83$ & $31.8 \pm 0.59$ & $470.5 \pm 89.56$ & $2.4 \pm 0.44$ & $0.37 \pm 0.1$ & $0.36 \pm 0.08$ & $1.62 \pm 0.27$ \\
\hline \multicolumn{13}{|c|}{$A g N P s$} \\
\hline & Male & $5.31 \pm 0.5$ & $9.38 \pm 0.99$ & $29.9 \pm 3.27$ & $56.4 \pm 1.44$ & $17.65 \pm 0.37$ & $31.3 \pm 0.56$ & $465.3 \pm 135.4$ & $2.2 \pm 1.8$ & $0.36 \pm 56.1$ & $0.38 \pm 0.07$ & $1.5 \pm 0.2$ \\
\hline & Female & $5.75 \pm 0.6$ & $10.2 \pm 1.07$ & $32.2 \pm 3.46$ & $55.9 \pm 0.99$ & $17.68 \pm 0.22$ & $31.58 \pm 0.17$ & $457.8 \pm 110.3$ & $2.25 \pm 2.9$ & $0.4 \pm 0.1$ & $0.39 \pm 0.09$ & $1.45 \pm 0.13$ \\
\hline
\end{tabular}

All data are expressed as means \pm SD and were compared with the ANOVA $(\mathrm{n}=6)$.

Differences with $P<0.05$ are considered statistically significant.

a) RBC: red blood cell. Hb: hemoglobin concentration. Ht: hematocrit. MCV: mean corpuscular volume. MCH: mean corpuscular hemoglobin. MCHC: mean corpuscular hemoglobin concentration. PLT: platelets. WBC: white blood cell. Lymp: lymphocyte. Mono: monocyte. Ganular:granular cells.

Table 4. Biochemical parameters of mice after treatment with colloidal AgNPs

\begin{tabular}{|c|c|c|c|c|c|c|c|}
\hline Day & Treatment & Creatinine & Cholesterol & Triglyceride & $\mathrm{SGOT}^{\mathrm{a})}$ & SGPT $^{\text {b) }}$ & Total Protein \\
\hline \multirow[t]{6}{*}{1} & Control & & & & & & \\
\hline & Male & $0.6 \pm 0$ & $125 \pm 26.1$ & $228.7 \pm 5$ & $83 \pm 31$ & $38.7 \pm 17.2$ & $5 \pm 0.3$ \\
\hline & Female & $0.6 \pm 0$ & $81.7 \pm 18$ & $157 \pm 23.6$ & $95.3 \pm 11.1$ & $33.3 \pm 10.8$ & $4.8 \pm 0.2$ \\
\hline & $A g N P s$ & & & & & & \\
\hline & Male & $0.5 \pm 0$ & $118 \pm 10.1$ & $154.3 \pm 43.2$ & $145 \pm 32.1$ & $28 \pm 11.5$ & $5.1 \pm 0.3$ \\
\hline & Female & $0.6 \pm 0.1$ & $87 \pm 12.1$ & $165 \pm 32$ & $107.3 \pm 27.9$ & $46 \pm 32.5$ & $4.7 \pm 0.2$ \\
\hline \multirow[t]{6}{*}{7} & Control & & & & & & \\
\hline & Male & $0.5 \pm 0.1$ & $140 \pm 27.9$ & $188.7 \pm 88.8$ & $46.3 \pm 10.1$ & $21 \pm 3$ & $5 \pm 0.1$ \\
\hline & Female & $0.6 \pm 0$ & $86.3 \pm 7.5$ & $127.3 \pm 23.2$ & $63.7 \pm 16$ & $12.7 \pm 3.5$ & $5.1 \pm 0.2$ \\
\hline & $A g N P s$ & & & & & & \\
\hline & Male & $0.6 \pm 0$ & $118.3 \pm 16$ & $189.7 \pm 44.4$ & $106 \pm 112.6$ & $84.3 \pm 119.2$ & $5.2 \pm 0.3$ \\
\hline & Female & $0.6 \pm 0$ & $84 \pm 8.2$ & $155 \pm 12.1$ & $82 \pm 33.5$ & $18.3 \pm 4.7$ & $5.6 \pm 0.4$ \\
\hline \multirow[t]{6}{*}{14} & Control & & & & & & \\
\hline & Male & $0.6 \pm 0.1$ & $145 \pm 23.6$ & $301 \pm 60.6$ & $47.7 \pm 21.1$ & $22.3 \pm 14.5$ & $5.1 \pm 0.3$ \\
\hline & Female & $0.6 \pm 0.1$ & $82 \pm 6.2$ & $150.3 \pm 49.1$ & $75.7 \pm 19$ & $25 \pm 16.5$ & $5.2 \pm 0.1$ \\
\hline & $A g N P S$ & & & & & & \\
\hline & Male & $0.5 \pm 0.1$ & $135.3 \pm 21.1$ & $242.3 \pm 62.4$ & $83.3 \pm 69.1$ & $29.7 \pm 9.6$ & $5 \pm 0.1$ \\
\hline & Female & $0.6 \pm 0$ & $86.7 \pm 9.1$ & $179.3 \pm 27$ & $67.3 \pm 15.5$ & $20.3 \pm 1.5$ & $5.3 \pm 0.2$ \\
\hline
\end{tabular}

All data are expressed as means \pm SD and were compared with the ANOVA $(\mathrm{n}=6)$.

Differences with $P<0.05$ are considered statistically significant.

a) SGOT: serum glutamic oxaloacetic transaminase.

b) SGPT: Serum glutamic pyruvic transaminase.

hr observation time (Fig. 3). However, no ocular reaction was found in all treated animals after $48 \mathrm{hr}$ post-exposure (Table 2). Histopathological examination of various organs in the control and treated animals showed no remarkable lesions that could be attributed to the effect of oral and dermal exposure of AgNPs at all observation times. Accumu- lation of free aggregated AgNPs was found on the epidermal layers of some 100,000 ppm treated animals (Fig. 4) and the mucosal areas of gastrointestinal tracts of the treated mice after $24 \mathrm{hr}$ post-exposure. However, no evidence of penetration or infiltration of AgNPs was observed in all accumulated areas. 

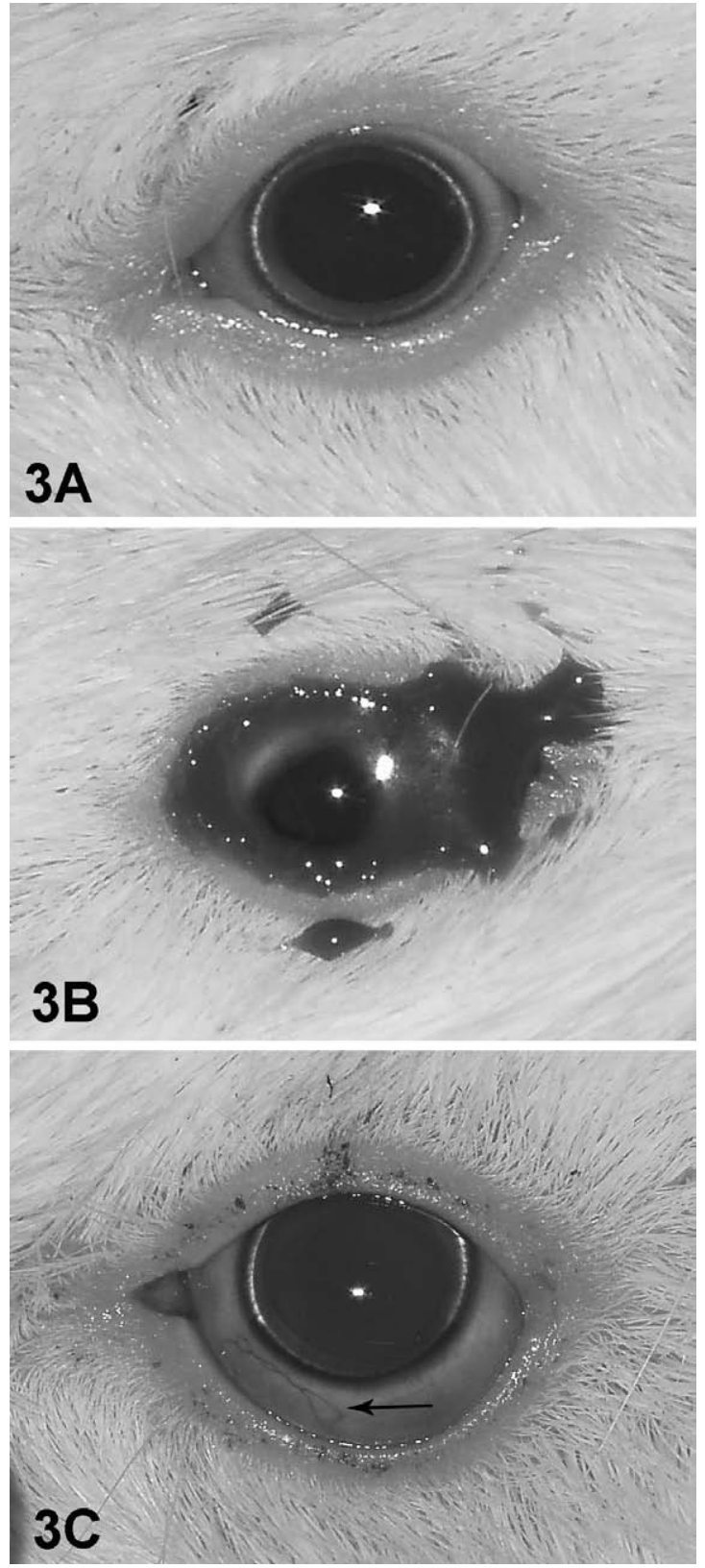

Fig. 3. Ocular appearances of control and 5,000 ppm groups were observed at various time points. No ocular lesion was found in the control (A) and 5,000 ppm group at $0 \mathrm{hr}$ postexposure (B). At $12 \mathrm{hr}$ post-exposure (C), the 5,000 ppm group revealed blood vessels hyperemia in conjunctivae (arrow).

\section{DISCUSSION}

The colloidal AgNPs in this study can be classified to the category of substances with low toxicity when taken for short periods of time. In the acute oral toxicity test, the mice treated with the dose of $5,000 \mathrm{mg} / \mathrm{kg}$ body weight showed
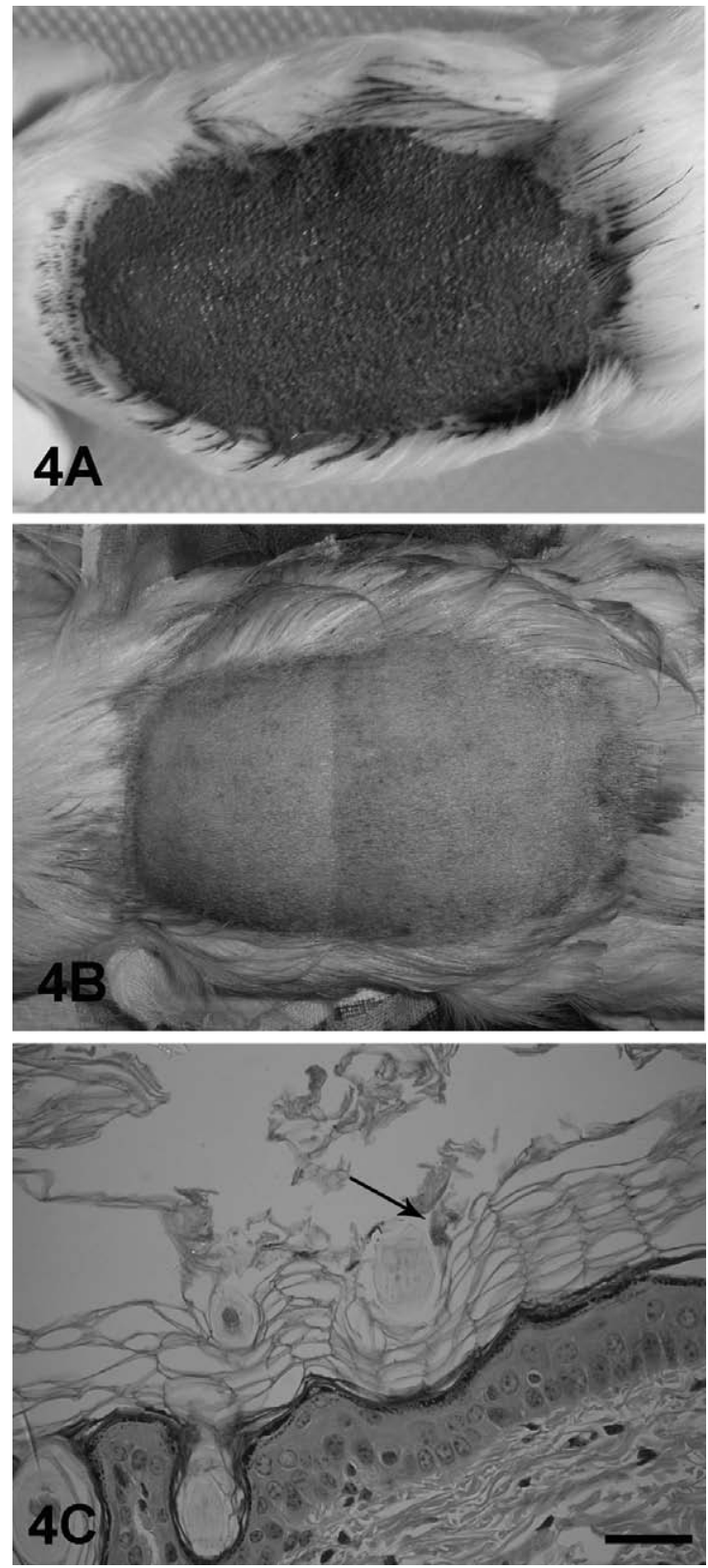

Fig. 4. Skin appearances of $100,000 \mathrm{ppm}$ group at $0 \mathrm{hr}$ postexposure (A) and $24 \mathrm{hr}$ post-exposure after residue removing (B) showed no remarkable lesions; Skin biopsy from the 100,000 ppm group (C) revealed brown-green clumps of colloidal AgNPs attached on the keratin layer (arrow). HE staining, bar $=390 \mu \mathrm{m}$.

no significant changes in behavior, clinical sign, percentage of body weight gain, hematological values, serum biochemical values and consistent pathological evaluation in various organs. In addition, no dead animal was noted during the observation time. The results of the acute oral toxicity study indicated that the $\mathrm{LD}_{50}$ of the colloidal AgNPs is greater 
than $5,000 \mathrm{mg} / \mathrm{kg}$ according to the OECD 425 guideline [27]. Substances with $\mathrm{LD}_{50}$ values greater than $5,000 \mathrm{mg} / \mathrm{kg}$ body weight are considered to show low toxicity. The body weight gain fluctuation in the early period of the experiment was observed in AgNPs male mice because of the aggressive behavior. Some of the mice in the dramatic decreasing body weight were suffered from bite wounds. However, the percentage weight gains gradually increase into the normal ranges after $24 \mathrm{hr}$ indicating the improvement of the nutritional state and behavior of the animals. The short term exposure to colloidal AgNPs, even in high dose of the eyes did not produce any toxic effects. The results of a single eye administration of colloidal AgNPS at low (50 ppm) or high doses $(5,000 \mathrm{ppm})$ did not induce any acute toxicological effects for 14 consecutive days observed. However, the transient mild conjunctival irritation was found in some animals from the 5,000 ppm treated groups at early $24 \mathrm{hr}$ postexposure.

Several case reports and in vitro studies have shown that silver can induce adverse immunological reactions and cellular damages to the skin. Activation and degranulation of mast cells by silver might contribute to the induction of allergic reactions and autoimmunity in the metal-exposed animals and humans $[9,25,28]$. In acute dermal toxicity test in this study, no evidences of immunological or cellular changes of the skin were observed throughout the experiments. Gross and microscopic evaluation did not find any abnormalities in epidermal and dermal layers in the exposed areas of the colloidal AgNPs treated groups compared to the controls.

Particle morphology plays a significant role in the toxicology of various kinds of nanoparticles $[16,24]$. The different shapes of particles can induce different biological responses and correlate to the severity of the tissue or cell injury. Several toxicity studies indicated that crystalline or fiber like particles can induce more toxic to cells as well as being more persistent in the tissues or organs [10, 20]. In the case of nanosilver particles, nanocrystalline silver particles are the most cytotoxic to cultured keratinocytes exposed to several types of silver as evidences of inhibiting cellular proliferation and changing cellular morphology of keratinocytes and fibroblasts [2, 22]. However, spherical or polygonal colloidal AgNPs in this study did not produce any pathological changes in any epidermal or dermal layer. No evidence of penetration or infiltration through the epidermal and dermal layers was observed throughout the observation period. Nevertheless, it has to be noted that acute dermal test in this study was carried out by in vivo conditions in which the cellular changes or behaviors may behave more different and complex from in vitro models. Further in vitro study should be performed to elucidate the toxic effects related to particle shape and size in cellular and molecular levels.

The releasing of silver ion $\left(\mathrm{Ag}^{+}\right)$during the preparation process of nanosilver particles may conduce to vary in toxicity. Colloidal AgNPs mediated biological effects in this study is independent of $\mathrm{Ag}^{+}$ions, because the releasing sta- tus of $\mathrm{Ag}^{+}$ions from colloidal AgNPs was absent or very low level. In addition, none of the toxic effects of the treated mice were observed in all toxicity tests. These results indicate that our colloidal AgNPs had no any acute toxic responses to the treated animals. However, in vitro and molecular studies are needed to elucidate the clear evidence of toxic mechanisms that will be related to $\mathrm{Ag}^{+}$. The toxic effects between AgNPs and dissolved $\mathrm{Ag}^{+}$still appear vague on results from several recent studies. Some investigators suggested that $\mathrm{Ag}^{+}$releasing from $\mathrm{AgNPs}$ in the aqueous state might induce inflammatory response and stimulate metallic detoxification processes [1, 11, 12, 21]. In contrast, several in vitro studies demonstrated that AgNPs involved in the damage of DNA and cell, carcinogenic process, oxidative stress formation, and metal detoxification $[3,8,13]$. Alternatively, a combination of both nanoparticle of silver and ionic $\mathrm{Ag}^{+}$may contribute to the toxic. The conclusion is still unclear in the details $[4,6]$.

In summary, the present study tried to modify various toxicity tests to verify the acute toxic effects of colloidal AgNPs. The colloidal AgNPs was found to be nontoxic when oral, ocular and dermal toxicity tests in mice and guinea pigs were performed. Further long-term toxicity, mutagenicity and carcinogenicity studies are required to clarify any adverse effects and are necessary to support the safe use of colloidal AgNPs.

ACKNOWLEDGMENTS. This work was supported by a grant from The National Research Council of Thailand, 2008. Some parts of the data in this study have been published in proceeding of the 4th Asian Society of Veterinary pathologists (ASVP) Conference, 19-20 November 2009, Bangkok, Thailand.

\section{REFERENCES}

1. Ahamed, M., AlSalhi, M.S. and Siddiqui, M.K. 2010. Silver nanoparticle applications and human health. Clinica. Chimica. Acta. 14: 1841-1848.

2. Arora, S., Jain, J., Rajwade, J.M. and Paknikar, K.M. 2008. Cellular responses induced by silver nanoparticles: in vitro studies. Toxicol. Lett. 179: 93-100.

3. Asharani, P.V., Wu, Y.L., Gong, Z. and Valiyaveettil, S. 2008. Toxicity of silver nanoparticles in zebrafish models. Nanotechnology 19: 255102.

4. Chae, Y.J., Chi, P.C.H., Lee, J., Bae, E., Yi, J. and Gu, M.B. 2009. Evaluation of the toxic impact of silver nanoparticles on Japanese medaka (Oryzias latipes). Aquat. Toxicol. 94: 320327.

5. Chen, X. and Schluesener, H.J. 2008. Nanosilver: A nanoproduct in medical application. Toxicol. Lett. 176: 1-12.

6. Foldbjerg, R., Olesen, P., Hougaard, M., Dang, D.A., Hoffmann, H.J. and Autrup, H. 2009. PVP-coated silver nanoparticles and silver ions induce reactive oxygen species, apoptosis and necrosis in THP-1 monocytes. Toxicol. Lett. 190: 156-162.

7. Hoet, P.H.M., Brüske-Hohlfeld, I. and Salata, O.V. 2004. Nanoparticles - known and unknown health risks. J. Nanobiotechnology. 2: 1-15.

8. Kim, S., Choi, J.E., Choi, J., Chung, K.H., Park, K., Yi, J. and 
Dy, Rui. 2009. Oxidative stress-dependent toxicity of silver nanoparticles in human hepatoma cells. Toxicol. In Vitro. 23: 1076-1084.

9. Kakurai, M., Demitsu, T., Umemoto, N., Ohtsuki, M. and Nakagawa, H. 2003. Activation of mast cells by silver particles in a patient with localized argyria due to implantation of acupuncture needles. Br. J. Dermatol. 148: 822.

10. Lam, P.K., Chan, E.S., Ho, W.S. and Liew, C.T. 2004. In vitro cytotoxicity testing of a nanocrystalline silver dressing (acticoat) on cultured keratinocytes. Br. J. Biomed. Sci. 61: 125127.

11. Lubick, N. Nanosilver toxicity: ions, nanoparticles-or both? 2008. Environ. Sci. Technol. 42: 8617.

12. Miura, N. and Shinohara, Y. 2009. Cytotoxic effect and apoptosis induction by silver nanoparticles in HeLa cells. Biochem. Biophys. Res. Commun. 390: 733-737.

13. Navarro, E., Piccapietra, F., Wagner, B., Marconi, F., Kaegi, R., Odzak, N., Sigg, L. and Behra, R. 2008. Toxicity of silver nanoparticles tochlamydomonas reinhardtii. Environ. Sci. Technol. 42: 8959-8964.

14. Ngeontaea, W., Janrungroatsakula, W., Maneewattanapinyo, P., Ekgasit, S., Aeungmaitrepiroma, W. and Tuntulania, T. 2009. Novel potentiometric approach in glucose biosensor using silver nanoparticles as redox marker. Sens. Actuators. 137: $320-326$.

15. Ngeontaea, W., Janrungroatsakula, W., Morakot, N., Aeungmaitrepiroma, W. and Tuntulania, T. 2008. New silver selective electrode fabricated from benzothiazole calyx [4] arene: Speciation analysis of silver nanoparticles. Sens. Actuators. 134: 377-385.

16. Oberdörster, G., Maynard, A., Donaldson, K., Castranova, V., Fitzpatrick, J., Ausman, K., Carter, J., Karn, B., Kreyling, W., Lai, D., Olin, S., Monteiro-Riviere., Warheit, D. and Yang, H. 2005. Principles for characterizing the potential human health effects rom exposure to nanomaterials: Elements of a screening strategy. Part. Fibre. Toxicol. 2: 8.

17. OECD. 2002. Test guideline 405. Acute eye irritation and corrosion. In: OECD guidelines for the testing of chemicals. Paris, France: Organization for Economic Cooperation and Development. Organization for Economic Cooperation \& Development (OECD).

18. OECD. 2001. Test guideline 425. Acute Oral toxicity test: the up and down procedure. In: OECD guidelines for the testing of chemicals. Paris, France: Organization for Economic Cooperation and Development. Organization for Economic Cooperation \& Development (OECD).

19. OECD. 2004. Test guideline 434. Acute dermal toxicity-fixed dose procedure. In: OECD guidelines for the testing of chemicals. Paris, France: Organization for Economic Cooperation and Development. Organization for Economic Cooperation \& Development (OECD).

20. Paddle-Ledinek, J.E., Nasa, Z. and Cleland, H.J. 2006. Effect of different wound dressings on cell viability and proliferation. Plast. Reconstr. Surg. 117: 110S-118S.

21. Park, E.J., Yi, J., Kim, Y., Choi, K. and Park, K. 2010. Silver nanoparticles induce cytotoxicity by a Trojan-horse type mechanism. Toxicol. In Vitro. 24: 872-878.

22. Poon, V.K. and Burd, A. 2004. In vitro cytotoxity of silver: implication for clinical wound care. Burns 30: 140-147.

23. Sereemaspun, A., Honpiticharoen, P., Rojanathanes, R., Maneewattanapinyo, P., Ekgasit, S. and Warisnoicharoen, W. 2008. Inhibition of human cytochrome P450 enzymes by Metallic nanoparticles : A preliminary to nanogenomics. Int. J. Pharmacol. 4: 492-495.

24. Sharma, M. 2010. Understanding the mechanism of toxicity of carbon nanoparticles in humans in the new millennium: A systemic review. Indian J. Occup. Environ. Med. 14: 3-5.

25. Suzuki, Y., Yoshimaru, T., Yamashita, K., Matsui, T., Yamaki, M. and Shimizu, K. 2001. Exposure of RBL-2H3 mast cells to $\mathrm{Ag}(+)$ induces cell degranulation and mediator release. Biochem. Biophys. Res. Commun. 283: 707-714.

26. Thomas, K. and Sayre, P. 2005. Research strategies for safety evaluation of nanomaterials, Part 1: Evaluating the human health implications of exposure to nanoscale materials. Toxicol. Sci. 87: 316-321.

27. Witthawasku, P., Panthong, A., Kanjanapothi, D., Taesothikul, T. and Lertprasertsuke, N. 2003. Acute and subacute toxicities of saponin mixture isolated from Schefflera leucantha Viguier. J. Ethnopharmacol. 89: 115-121.

28. Yoshimaru, T., Suzuki, Y., Inoue, T., Niide, O. and Ra, C. 2006. Silver activates mast cells through reactive oxygen species production and a thiol-sensitive store-independent $\mathrm{Ca}^{2+}$ influx. Free Radic. Biol. Med. 40: 1949-1959. 